\title{
Enhanced performance of a green inorganic-based passive film on the batch hot-dip galvanized steel by organic additives
}

\author{
Yongfeng Long*, Changsheng Liu*, Sunjuan Peng \\ College of Materials Science and Engineering, Northeastern University, Shenyang113024, China \\ *E-mail: yongyeyongfeng@126.com, csliu@ mail.neu.edu.cn \\ doi: $10.20964 / 2020.03 .44$
}

Received: 23 October 2019 / Accepted: 19 December 2019 / Published: 10 February 2020

\begin{abstract}
Till date, there are extremely limited reports on the green passivation technologies for the batch hot-dip galvanization. Herein, an environmental-friendly passivation route for batch hot-dip galvanization using reactive inorganic salts along with little organic substances, such as silane and rust-proof wax emulsion, as additives was developed. The effect of presence of organic additives on the performance and formation process of the inorganic-based passive film were studied via neutral salt spray test, surface contact angle measurement, electrochemical tests, scanning electron microscopy, and energy dispersive $\mathrm{X}$-ray spectroscopy. The results show that the additives significantly enhanced the corrosion resistance and reduced surface tension of the passive film. The additives did not participate in the reaction with zinc layer and no clear change in overall morphology of passive film was observed. However, a concentration of additives was formed on the film's surface to prevent the penetration of corrosive medium into the film. Overall, the organic additives even at low amounts could dramatically improve the comprehensive performance of the passive film, which would be useful for industrial applications in a low-cost and environmental-friendly way.
\end{abstract}

Keywords: Batch hot-dip galvanization; Environmental-friendly passivation; Organic additives; Enhancement of performance.

\section{$\underline{\text { FULL TEXT }}$}

(C) 2020 The Authors. Published by ESG (www.electrochemsci.org). This article is an open access article distributed under the terms and conditions of the Creative Commons Attribution license (http://creativecommons.org/licenses/by/4.0/). 